\title{
El orden trascendental en Zubiri
}

José Alfonso Villa Sánchez

\section{Resumen}

El tema del orden de lo trascendental en el ser, y la estructura de los trascendentales, mantuvo en vilo, en buena medida, el pensar de la filosofía y la teología de la edad media. Xavier Zubiri se sabe heredero de esta tradición; pero se sabe también heredero de la fenomenología de Husserl y de la ontología fundamental y hermenéutica de Heidegger. Frente a la tradición, y al mismo Heidegger, Zubiri afirma la preeminencia del momento de realidad respecto del momento de ser en las cosas. Esta preeminencia de la realidad respecto del ser trastoca el orden trascendental mismo ya que lo adscribe a la realidad y no al ser; y exige que el orden trascendental y su estructura se construya de una manera diferente a como lo hizo la tradición desde el horizonte del ser. En este texto recogemos y exponemos el problematismo sobre el orden transcendental en la filosofía de Zubiri, confrontamos este problematismo con la filosofía de los trascendentales de la tradición, nos detenemos en algunos de los nudos que aparecen a la hora de dar cuenta del orden trascendental y, en algunos casos, atisbamos alguna solución. En las postrimerías de la investigación filosófica, el orden trascendental y su estructura conservan su carácter de problemático y su carácter de abierto.

\footnotetext{
Doctor en Filosofía por la Universidad Iberoamericana de la Ciudad de México. Profesor investigador en el Instituto de Investigaciones Filosóficas "Luis Villoro" de la Universidad Michoacana de San Nicolás de Hidalgo, en Morelia, México. Contacto: alphonsovilla@gmail.com.
} 


\title{
Palabras clave
}

Metafísica, trascendentales, orden, realidad, ser.

\section{The transcendental order in Zubiri}

\begin{abstract}
The topic of order of the transcendental aspect in the being, as well as the the structure of the transcendental ones, kept on tenterhooks the act of thinking about philosophy and-theology, in the Middle Ages. Xavier Zubiri is known as an inheritor of this tradition; but also known as an inheritor of the Husserl's phenomenology and Heidegger's fundamental and hermeneutic ontology. Opposite to the tradition, and to Heidegger's, Zubiri affirms himself on the preeminence of the moment of reality respect to the things' moment to be. This preeminence of reality respect to the being, modifies the transcendental order itself since it assigns it to reality and not to the being; so that it is required the transcendental order and its structure to be constructed differently from the way the tradition did, parting from the horizon of the being. In this text we gather and expose the problem on the transcendental order in Zubiri's philosophy, confront this problem with the philosophy of the tradition transcendental ones', in order to stop in some of the knots that appear at the moment of realizing the transcendental order and, in some cases, to see some solution. In the twilights of the philosophical investigation, the transcendental order and its structure preserve both its problematic and open character.
\end{abstract}

\section{Keywords}

Metaphysical, transcendental, order, reality, being. 


\section{Introducción}

La metafísica escolástica se ocupó del ser en cuanto ser, de su estructura y de sus propiedades. Porque el ser es el más universal de todos los conceptos y de todas las cosas fue colocado en un orden diferente al de los géneros y las especies: fue colocado en el orden trascendental. Zubiri no puede simplemente obviar esta tradición y su problemática en una filosofía primera de la realidad, la cual tiene como una de sus actualizaciones el ser en el mundo.

En este artículo veremos la crítica que Zubiri hace al orden trascendental de la escolástica, al tiempo que va esbozando su propia idea del orden trascendental adscrito a la realidad y no al ser.

\section{El problema}

El asunto de los transcendentales, o para decirlo ontológicamente con más precisión, de lo trascendental, es decir, de aquello que debe predicarse del ser en tanto que ser, mantuvo en vilo el pensamiento filosófico de la Escolástica ${ }^{1}$.

«La première formulation thematiqué de la doctrine des transcendentaux - sans doute dans la Summa de Bono du Chancelier Philippe [m. 1236] - montre clairement le contexte néoplatonicien et avicennien aun sein duquel surgit pour la première fois l'étude des propiétés de l'être: le concept central, venu en droite ligne de la traduction d'Avicenne, est en effet celui de condiciones concomitantes, et il désigne l'ensemble des déterminations qui accompagnent a priori le concept de l'être. On peut lire dans la Metaphysica d'Avicenne, à propos de l'unité: Unitas est quidam concomitans substantiam...; es de univesalitate forum quae comitantur res». Jean-Francois Courtine, Suarez et le système de la métaphysique (Paris: Presses Universitaires de France, 1990), 355. Étienne Gilson está de acuerdo también con los estudiosos que conceden a Felipe el Canciller «el honor de haber escrito el primer tratado acerca de las propiedades trascendentales del ente: la unidad, la verdad y la bondad (Pouillon). Se trata ya de un problema esencialmente filosófico, tratado como tal por Felipe y, sin embargo, integrado por él mismo en una obra esencialmente teológica. El uso que hace de Aristóteles y de los filósofos árabes basta para probar que, en adelante, la teología cristiana no podrá esquivar el encuentro con dichos autores (...) Felipe depende de Guillermo de Auxerre; Juan de la Rochela y otros después de él unirán sus esfuerzos a los de Felipe; Alberto Magno beberá en los escritos de Juan de la Rochela. Así, continuándose, criticándose y completándose mutuamente, estas obras irán definiendo progresivamente el plan de aquella otra que muy pronto realizará Santo Tomás de Aquino». Étienne Gilson, La Filosofía en la Edad Media. Desde los orígenes patrísticos hasta el fin del siglo XIV (Madrid: Gredos, 1999), 409. 
Ya Aristóteles vio que la universalidad que debía corresponder a los predicados del ser en tanto que ser debía estar por arriba de la universalidad de los géneros, las especies y las diferencias específicas².

La Escolástica llamó a esos caracteres del ente en tanto ente «trascendentales», y las diversas escuelas matizaron, desde sus propias perspectivas, tanto su naturaleza como su estructura u orden en tanto que caracteres del ente en tanto ente ${ }^{3}$. Pronto aparecieron las dificultades con el aliquid, pero sobre todo con el verum y con el bonum. Estas dificultades lo que mostraban era, por lo menos, que no todos los trascendentales lo eran del mismo modo. Así, aliquid no era un trascendental con el mismo modo de radicalidad que ens, res y unum; igual debía decirse del verum y del bonum.

\section{El orden trascendental}

El orden riguroso de la estructura trascendental escolástica, especialmente en Santo Tomás, sería el siguiente: ens, res, unum,

Teresa Oñate y Zubía lo explica del siguiente modo: «El punto de partida de la metafísica aristotélica, enteramente configurada a partir de él, consiste precisamente en sentar que el ente no es género (Cf. sobre todo en: Met. B (III)-3, 998b 21-999a 6-16; D (V)-28, 1024b 8; H (VIII)-6 1045a 34; I (X)-2, 1053b 16; y también en Z (VII)-3, 13-16/; Tóp., IV-1, 121a 11/; Anal. Post., II-7,92b 13). Y, mucho menos, el género supremo o universalísimo (esta noción resulta a Aristóteles absurda, contradictoria y vacía. Cf. Anal. Post., II-19, 100b 1). La filosofía primera no puede, entonces, ser un saber sobre "el objeto más universal y más abstracto", según la elocuente fórmula de Natorp, porque el "ser" aristotélico no es un universal genérico común a todos los entes ("forma general", decía Jaeger): si así fuera no sería real: ousía o entidad. Dice Aristóteles: “Nada común es ousía (entidad); la ousía no está en nada más que en sí misma y en lo que la tiene, de lo cual es ousía" (Met. Z-16, 1040b 24). O en otros términos: "Parece imposible, en efecto, que sea ousía cualquiera de los llamados universales. Pues en primer lugar, es ousía de cada cosa lo que es propio de cada cosa y no se da en otra; pero el universal es común, pues se llama universal aquello que por su naturaleza puede darse en varios" (Met. Z-13, 1038b 9-13). "Además se llama ousía a lo que no se predica de un sujeto; pero el universal se dice siempre de un sujeto" (Met. Z-13, 1038b 16). Esta tesis: que el universal genérico no es substancia, por resultar tan constitutiva como decimos, se halla muy poco aislada en el aristotelismo: inspira, en particular, todo un aspecto de la polémica antiplatónica; el referente a la Teoría de las ideas, como "universales separados". No obstante, el filósofo dedica a mostrarla dentro de los metafísicos, especialmente, los largos desarrollos que se extienden del capítulo 12 al 16, del libro Z, consagrados a la teoría de la ousía». Teresa Oñate y Zubía, Para leer la Metafísica de Aristóteles en el siglo xxı. Análisis crítico hermenéutico de los 14 lógoi de Filosofía primera (Madrid: Dykinson, 2001), 39-40.

3 Son clásicas las discusiones sobre todo entre tomistas y escotistas. Cf. Luis Alberto De Boni, «La metafísica escotista de Dios en el De Primo Principio. Duns Escoto y el argumento anselmiano del Proslogion» en La Filosofía Medieval, ed. Francisco Bertelloni - Giannina Burlando (Madrid: TrottaCSIC, 2002), 195-216; Jean-Francois Courtine, op. cit., 323-401. 
aliquid, verum, bonum ${ }^{4}$. Zubiri explica cuál es el orden riguroso de esos seis trascendentales en la estructura del ente en tanto ente para la Escolástica. "No se trata de una simple enumeración, sino que entre estos momentos entitativos existe una interna fundamentación. La Escolástica admite, pues, innegablemente un estricto orden trascendental $»^{5}$.

El primer lugar, el fundamento de la estructura trascendental, lo dan el ens y la res. En rigor se trata sólo de dos expresiones del ente: "Ens significa que la cosa "es"; y res significa "aquello" que la cosa es; es decir, su ordenación al esse; sin esta ordenación aptitudinal al esse la cosa sería "nada"»". Podríamos decir, desde la metafísica zubiriana, que res en tanto que «aquello» que la cosa es nombra la talidad de la cosa, mientras que ens nombra la realidad «de suyo» de la cosa. Obviamente esto requiere ulteriores explicaciones. Nos sirve, sin embargo, la equivalencia comparativa porque Zubiri conserva deliberadamente el orden trascendental, aunque suscrito a la realidad en cuanto tal y no al ente. De cualquier modo, para la Escolástica, «aquello» que la cosa es, es decir, la res, está ordenada al ens, al esse. Sin ese ordenamiento al ser, al ens, no habría res, no habría «aquello». Así que la res en tanto que «aquello» (talidad) que la cosa es remite al ser: sin tal ordenación sería nada. El ens y la res no son dos propiedades de la cosa que es. Esto sería imposible y un contrasentido. Por el contrario, «ens y res son perfectamente sinónimos y expresan con dos vocablos no una propiedad trascendental,

4 Cf. Ibíd., 365.

$5 \quad$ Xavier Zubiri, Sobre la esencia (Madrid: Alianza-FXZ, 1998), 418. La expresión «orden trascendental» para nombrar la estructura del ente en tanto ente es de Santo Tomás, De Veritate, xxI, 3. Zubiri nos precisará su concepto de orden trascendental primeramente en tanto que orden: «Orden no significa (...) el dominio, la línea o la dirección según la cual consideramos la realidad, esto es, la consideración trascendental a diferencia de la consideración meramente talitativa, sino que entiendo por orden trascendental la estructura misma de la realidad en su transcendentalidad, por razón de su carácter transcendental. Orden significa, pues, estructura interna» Xavier Zubiri, op. cit., 417-418. Parece que Duns Escoto gustaba hablar más bien de «trascedens ut trascendens (Opus ox., dist. VIII, q. III) -"los trascendentes como trascendentes"-». Ver las entradas «Trascendental» Y «Trascendentales» en José Ferrater Mora, Diccionario de Filosofía (Barcelona: Ariel, 2001), 3570.

Xabier Zubiri, op. cit., 418. 
sino lo trascendental mismo» ${ }^{7}$. Digámoslo así: el ente en tanto que ente es a) la cosa que es (ens) y b) «aquello» que la cosa es (res). Realidad y talidad, en palabras de Zubiri. Lo trascendental mismo es igual a ens-res. Si todos los caracteres de ser son intercambiables con él, estos dos son el ser mismo.

Por lo que ve al orden trascendental, en la línea de lo más fundamental, la Escolástica en general aceptó que las cosas eran así sin mayores problemas. Los problemas van a venir con el unum y el aliquid; pero sobre todo con el verum y el bonum. Respecto del unum y el aliquid dice Zubiri que los escolásticos pensaron que se trataba de dos momentos intrínsecos del ente, pero formalmente negativos. "Aliquid no es sino el quid en cuanto no es otro quid. Unum no es en sí mismo sino la negación de la indivisión»». El aliquid lo que dice es que este ente es este ente; que este ente no es aquel otro ente. En la primera enunciación aparece una redundancia; en la segunda se trata de una negación, y por tanto de un imposible. El unum lo que dice es que este ente es sólo y nada más este ente; que el ente en tanto que ente no es dos sino que el ente en tanto que ente es uno, es decir, indiviso. La Escolástica se metió en unos atascos tremendos por la imposibilidad de conceptuar positivamente el unum y el aliquid. Pero, a pesar de todo, los mantuvo como trascendentales.

\section{Las «funciones trascendentales»}

Zubiri, por su parte, quiere sacarles el partido positivo que ambos tienen. Porque sigue siendo cierto en su metafísica que cada realidad sustantiva es una (indivisa) y que cada realidad-sustantiva-una es esta y no otra. Pues bien, el unum y el aliquid, momentos intrínsecos pero negativos del ente, desempeñan una «función trascendental», distinta cada uno. Ya la Escolástica pensó que el unum, con ser negativo pero intrínseco al ente, «connotaba» o «incluía» algo positivo: «la positiva

7 Ídem.

8 Ídem. 
entidad indivisa del ente» ${ }^{9}$. Pero el unum no connota ni incluye nada. Más bien: «La índole positiva de la intrínseca indivisión del ente es la que desempeña una función trascendental en orden a la unidad $»^{10}$. El ente es, positivamente, intrínsecamente indiviso. Esta intrínseca indivisión del ente es su índole positiva. Y esta índole positiva es la que desempeña la función trascendental en orden al unum. Veámoslo así: la indivisión ad intra del ente en tanto ente funciona siempre ordenando al ente en tanto unum, en tanto un ente. Así que aquí hay una cadena formal funcionando trascendentalmente: $a$ ) el ente en tanto ente es indiviso, b) esta indivisión es su índole positiva, $c$ ) esta índole positiva que es la indivisión del ente en tanto ente desempeña una función trascendental sobre el ente en tanto ente, $d$ ) la función trascendental que desempeña la índole positiva de la intrínseca indivisión del ente es para que el ente en tanto ente sea uno. Sólo invirtiendo así los términos, y dislocando el unum de su definición negativa, es posible conservarlo como aquello hacia lo que está ordenada la índole positiva de la intrínseca indivisión del ente por su función trascendental.

Con el aliquid sucede también que para la Escolástica es un trascendental intrínseco al ente, pero negativo. El aliud es la alteridad del quid; el ente en tanto ente es aliquid. Es este y no es aquel otro. $\mathrm{O}$ aquel otro no es este. El ente es aliquid. Igual que con el unum, la Escolástica se atascó con el aliquid. Zubiri cree salvar estos atascos diciendo que «lo decisivo... [es] la necesidad metafísica de esta multitud que -al igual que la positiva entidad en el caso del unum-, si bien no pertenece al ente como "propiedad" trascendental suya, sin embargo, desempeña una "función trascendental" $\gg 1$. Aquí también hay que invertir los términos para dar con el aliquid en tanto trascendental. Se parte del hecho de la multiplicidad del ente, aunque esta multiplicidad no sea un trascendental del ente en tanto ente. Sin embargo, que factualmente el ente es múltiple tiene una función trascendental ${ }^{12}$.
Ibíd., 420.
Ibíd., 421.
Ibíd., 422.
Cf. Ídem. 
Es necesario metafísicamente que el ente sea múltiple. Aunque al ente en tanto que ente ni le va ni le viene tal multiplicidad, pues el ente en tanto ente será ente haya o no múltiples entes. Sin embargo, la multitud del ente es un hecho. Y es esta multitud del ente la que funciona trascendentalmente, posibilitando la propiedad trascendental del aliquid: la referencia del alter al unum hace del ente en tanto ente un aliquid. Si con el ens y con la res prácticamente las dificultades de la Escolástica fueron menores, no sucedió así con el unum y el aliquid. De hecho, Zubiri cree que no solucionaron sus intrínsecas dificultades adecuadamente y por eso postula la inversión de los términos y la inclusión de la idea de «función trascendental». Esto no significa que Zubiri vaya a aceptar sin más el orden trascendental de la Escolástica. Pero se hace rigurosa cuestión del problema.

Los problemas, por su parte, que el verum y el bonum le plantearon a la Escolástica fueron mayúsculos. En primer lugar estaba el asunto de si se trataba de dos momentos del ente en cuanto ente. La casi totalidad de la Escolástica piensa que se trata de dos momentos positivos del ente: de dos momentos positivos «sólo por ser dos respectos extrínsecos del ente en cuanto tal a un ente determinado, la psijé, el ánima inteligente y volente» (SE 422) ${ }^{13}$.

Ídem. En cuanto a la estructura del orden trascendental, Zubiri mostrará estar más cerca de la línea marcada por Tomás de Aquino que de la línea que sigue Duns Escoto. Se pueden contrastar las posturas de ambos en Jean-Francois Courtine, op. cit., 374. Mientras Santo Tomás parte del ente real para levantar el orden trascendental, Duns Escoto parte de la univocidad del ente y de su virtualidad. Así lo explica Gilson: «Tomado en su aptitud lógica para ser predicado indistintamente de cuanto es, el ser es la más vacía de las formas; de cualquier modo que se le considere, ningún conocimiento real puede salir de él. Por el contrario, el ser del metafísico es una realidad; sus virtualidades son muy ricas, y encerrarse en él no es entrar en un callejón sin salida. El ser en cuanto ser tiene propiedades: las primeras son sus modos. Los modos de una naturaleza o esencia son sus determinaciones intrínsecas posibles. Tomemos el ejemplo de un rayo luminoso (...) De manera semejante, hay modos de ser, es decir -según indica el nombre mismo-, "maneras de ser", que no son sino el mismo ser, diversamente modificado, desde luego, pero siempre en cuanto ser. Los dos primeros modos del ser son lo finito y lo infinito. Es la primera división del ser, e incluye a todas las demás. Efectivamente, es anterior a la división aristotélica del ser en las diez categorías, porque toda categoría es una determinación y, por tanto, una limitación, de modo que el ser al que se aplican las categorías entra con pleno derecho en la modalidad finita del ser. Demostrar la existencia de Dios, para el metafísico, es probar que el "ser infinito" es o existe. Limitada por la misma naturaleza de su objeto, que es el ser, la metafísica no podría ir más lejos, pero puede llegar hasta ahí». Étienne Gilson, op. cit., 580. 
Si el unum y el aliquid abrieron para la Escolástica tal nube de problemas, abordado el asunto por el lado de la indivisión y la alteridad pero, al fin y al cabo tratándose de propiedades, aunque negativas, del ente en cuanto ente, podemos imaginar lo que sucedió con el verum y el bonum cuyo carácter positivo respecto del ente en cuanto tal era ya problemático, a más de lo problemático de la respección del ente en cuanto ente a un ente inteligente y volente que diera origen al verum y al bonum en tanto trascendentales. Ya la Escolástica vio que «nada hay en el ente en cuanto ente que incluya en su razón formal la existencia de un ente inteligente y volente». De cualquier modo, el verum y el bonum fueron para la Escolástica trascendentales en cuanto respectos extrínsecos del ente en cuanto ente al ente inteligente y volente. Pero Zubiri también aquí va a invertir el orden del análisis de los términos para arrojar luz sobre el problema. Lo primero que debe decirse es lo siguiente: «la inteligencia y la voluntad del ente inteligente y volente no son formalmente atributos o caracteres de su entidad en cuanto tal; esto es, inteligencia y voluntad no son momentos trascendentales del ente inteligente y volente, sino momentos de su modo especial de ser, momentos de su talidad» ${ }^{14}$.

Esto es verdad: sería un contrasentido que la inteligencia y la voluntad fueran propiedades trascendentales del ente inteligente y volente en cuanto ente. Son, en todo caso, propiedades del ente inteligente y volente en cuanto ente inteligente y volente, no en cuanto mero ente. Pero la inteligencia y la voluntad, propias sólo del modo especial de ser del ente inteligente y volente, de su talidad y no de su nuda realidad, «tienen una estricta "función trascendental"..., puesto que sólo en vistas a la inteligencia y a la voluntad tiene el ente en cuanto tal las propiedades trascendentales de verdad y bondad $»^{15}$. Otra vez: por el hecho inconcuso de que hay talitativamente ente

14 Xavier Zubiri, op. cit., 423-424.

15 Ibíd., 424. 
inteligente y volente en función trascendental, hay el verum y el bonum del ente en cuanto ente.

Con las «funciones trascendentales» que incluye en el orden trascendental de la Escolástica junto a lo trascendental mismo, ens y res, y junto a las propiedades de lo trascendental, unum y aliquid, verum y bonum, Zubiri pretende haber desatascado el problema escolástico, aunque, como ya dije, esto no signifique necesariamente que lo asuma tal cual para su propia metafísica. Por el contrario, critica el orden trascendental tal como lo propone tanto la Escolástica ${ }^{16}$ como la filosofía moderna.

\section{El orden trascendental de la realidad}

\section{a. Problema}

Aunque ambas filosofías coincidan en que «es trascendental aquello en que todo conviene» ${ }^{17}$, la filosofía primera de Zubiri no suscribirá la idea escolástica de adscribir el orden trascendental al ente en cuanto ente, y mucho menos la idea moderna que lo adscribe al yo puro en tanto condición epistemológica y ontológica del objeto. «Para el idealismo, lo que es trascendental es la posición del yo puro; inscribe, por tanto, la idealidad dentro de la transcendentalidad, y con ello, el orden trascendental es el orden de la realidad en cuanto objeto. Pues bien, para la Escolástica, lo que es trascendental es el ser; inscribe, por tanto, el ser dentro de la transcendentalidad, y con ello, el orden trascendental es el orden de la realidad en cuanto ente» ${ }^{18}$.

Aunque Zubiri sigue, como ya dijimos, la estructura del orden trascendental de Santo Tomás, asume sin embargo algunas ideas de Scoto, como la de «disyunción» aplicada por el Doctor Sutil a algunas de las pasiones propias del ente tales como finitud-infinitum, actus, potentia, etc. Zubiri dirá que mundo es un trascendental disyunto. Cf. Ibíd., 431. Ibíd., 388

18 Ibíd., 389. En las páginas iniciales de la Crítica de la razón pura escribe Kant del siguiente modo: «Haré ahora una observación que debe tenerse presente y cuya influencia se extiende a todas las consideraciones que siguen: no todo conocimiento a priori debe llamarse trascendental (lo que equivale a la posibilidad del conocimiento o al uso de este a priori), sino sólo aquél mediante el cual conocemos que determinadas representaciones (intuiciones o conceptos) son posibles o son empleadas puramente a priori y cómo lo son. Por ello, ni el espacio ni ninguna determinación geométrica a priori del mismo constituye una representación trascendental. Sólo puede llamarse representación trascendental el conocimiento de que tales representaciones no poseen origen empírico, por una parte, y, por otra, la posibilidad de que, no obstante, se refieran a priori a objetos de la experiencia. 
Pero Zubiri piensa que trascendental qua trascendental es la realidad misma, no el ser ni el yo puro (Kant, Husserl). Del concepto de realidad en la metafísica de Zubiri no nos hacemos ya, por el momento, ninguna cuestión. Aunque sí del concepto de orden o estructura trascendental que sobre la realidad se afinca. Porque en esta estructura trascendental es donde aparece el ser o, por lo menos, debería aparecer. Y es que los textos de Zubiri parecen ambiguos y desconcertantes en este punto. Así, en Sobre la realidad encontramos esta idea, que no aparece en Sobre la esencia, ni en ningún otro lugar de su obra: «El ser es justamente aquello según lo cual las cosas complexas, las cosas que constituyen una simploké una conexión en el mundo en tanto que cosas reales, son actuales en él» ${ }^{19}$.

Hasta aquí no hay, aparentemente, ningún problema. Es exactamente lo que Zubiri nos ha explicado sobre el ser en tanto actualidad. Pero después continúa del siguiente modo: «aquello que funda, por consiguiente, los trascendentales es el ser» ${ }^{20}$. Aquí empiezan los sobresaltos. El editor de esta obra nos ha puesto una llamada a pie de página donde dice que al margen de estas últimas cinco líneas hay una nota de Zubiri: «Ojo. Esto no es verdad sin más» ${ }^{21}$. Me permito tomar de nuevo la última cita y continuar el texto para que se vea con qué es con lo que aquí Zubiri tiene dificultad: «... aquello que funda, por consiguiente, los trascendentales es el ser [nota 22: "Ojo. Esto no es verdad sin más"]. El verum, el bonum y el aliquid son dimensiones del ser y no simplemente de la nuda realidad [nota 23] $»^{22}$.

De la misma forma sería también trascendental el uso del espacio aplicado a objetos en general. Pero si se aplica sólo a los objetos de los sentidos, tal uso se llama empírico. La diferencia entre lo empírico y lo trascendental sólo corresponde, pues, a la crítica del conocimiento y no afecta a la relación entre éste y su objeto» B 80-81. Cf. A 565. Zubiri discute de manera crítica y copiosa el concepto de lo trascendental en la filosofía moderna. Cf. Xavier Zubiri, op. cit., 373-383; Xavier Zubiri, Sobre la realidad (Madrid: Alianza-FXZ, 2001), 80-90.

19 Xavier Zubiri, Sobre la Realidad, op. cit., 144.

20 Ibíd., 144.

21 Ídem, nota 22.

22 Ídem. 
La nota 23 del editor dice: «Al margen de esta última frase aparece un NO rodeado por un círculo» ${ }^{23}$. Páginas más adelante Zubiri explica que «el verum, el bonum y el aliquid no sólo no son momentos directos de la realidad, sino que son momentos del ser de la realidad, es decir, de la actualidad de la realidad sustantiva en esa respectividad que llamamos mundo [nota 30]» ${ }^{24}$. En la nota número 30 el editor nos dice que al margen de este párrafo Zubiri escribió: «Ojo. Ver la pag. 144». En definitiva, lo que estas notas marginales indican es que, en primer lugar, Zubiri está seguro de que lo trascendental tiene una estructura, un orden; pero, en segundo lugar, de lo que no está seguro es de cuál sea la estructura precisa de lo trascendental.

Vamos a ir primero a un texto de Sobre la Esencia para mirar ahí cuál es la estructura de lo trascendental y luego lo compararemos con un texto de Sobre la realidad. Veremos a dónde llegamos. En Sobre la Esencia dice Zubiri:

en definitiva, el orden transcendental es el orden de las cosas reales en cuanto reales, esto es, como algo "de suyo". Estas cosas son "de suyo" en y por sí mismas; son los transcendentales simples (res y unum). Y son también "de suyo" respectivas; son los transcendentales complejos, bien disyuntos (mundo), bien conjuntos (aliquid, verum, bonum), de los cuales estos se fundan en los disyuntos. Ésta es la estructura transcendental de la realidad, una estructura determinada por la talidad en "función" transcendental. Esta estructura transcendental reposa, pues, sobre dos transcendentales primeros: realidad y mundo; transcendental simple aquel, transcendental complejo éste ${ }^{25}$.

Obviamente, este apretado párrafo requiere varias explicaciones. Sorprende, de entrada, que el ser no aparezca en esta estructura transcendental. En los textos que citábamos de Sobre la realidad aparecía el ser como el fundamento para el aliquid, el verum y el bonum. Pero ya hicimos notar que Zubiri tenía sus dudas. Vayamos, pues, por partes. Dicho simplemente así por el momento, Zubiri adscribe el orden trascendental al «orden de las cosas reales en cuanto

Xavier Zubiri, Sobre la Esencia, op. cit., 432. 
reales ${ }^{26}$. No al ser en tanto ser, de la Escolástica, ni mucho menos al yo puro. El orden trascendental es el orden, la estructura, que las cosas reales en cuanto reales factualmente tienen. Realidad es aquello que es «de suyo» eso que es. No es aquello que queda en mí en tanto que objeto de una cosa en sí ya siempre incognoscible, y sólo manifestada fenoménicamente. Tampoco es esa cosa extra animam de la Escolástica, que esté o no el ente inteligente y volente, sigue siendo lo que es. Realidad es eso que la cosa es «de suyo»: en cierto modo en sí misma; pero en cierto modo actualizada en la inteligencia sentiente. Bien, pues es a la realidad así entendida a la que debe irse para describir el orden y la estructura trascendental que así se opera.

\section{b. Trascendentales simples}

Para Zubiri los primeros trascendentales son la res y el unum. Son propiedades de las cosas reales «de suyo» «en y por sí mismas»» ${ }^{27}$. Toda cosa que es "de suyo» eso que es, es realidad, es res. Ser «de suyo», por tanto, es ser res, ser realidad. La cosa «de suyo» tiene unas notas con las que se actualiza para estar siendo lo que es. Sabemos ya que lo que nombra el concepto de «actualización» es nodal. Y así hay por lo menos tres tipos de actualización de lo real: a) Por una primera actualización de las notas en la cosa misma «de suyo», queda la cosa siendo lo que es y para poder ser lo que es. Aquí nos movemos en el ámbito de la cosa misma «de suyo». b) Pero hablamos también de una segunda actualización de la cosa real «de suyo» frente a otras cosas reales también «de suyo». Esta segunda actualización es diferente y formalmente posterior a la primera. Porque en aquella las notas se actualizan para que la cosa sea «de suyo» lo que es ella misma. Pero en la segunda actualización es la cosa ya siendo «de suyo» lo que es la que se actualiza frente a otras cosas reales también «de suyo». Es la actualización en el mundo que es el ser. c) La tercera actualización es la de la cosa real, siendo «de suyo» lo que es junto y frente a otras cosas reales, en la inteligencia sentiente, en el hom- 
bre. El conocimiento, en su sentido más elemental, no es más que la actualización de la cosa real siendo «de suyo» lo que es frente a otras cosas reales, en la inteligencia sentiente.

1. res

El primer trascendental de las cosas reales es, pues, res: que la cosa real es «de suyo» aquello que es. Cosa real, res, «de suyo», y trascendental, en este nivel, son absolutamente intercambiables. Las cosas, pues, primordialmente son "de suyo», son res, son alteridad absolutamente relativa. Por un imposible metafísico, este «de suyo» en tanto alteridad absolutamente relativa indica, por el lado absoluto, que si la realidad inteligente se diera la vuelta y se fuera, la realidad tal seguiría siendo «de suyo» lo que es. Pero indica también, por su lado relativo, que la res «de suyo» es lo que es tan sólo actualizada en la inteligencia sentiente y, en estricto sentido, sólo mientras dura la actualización en persona, para seguir en la línea de Husserl ${ }^{28}$. La Escolástica sustantivó el ser, lo dividió e hizo del «de suyo» un tipo de realidad, el esse reale. Así lo explica el mismo Zubiri: «Esse, ser puede considerarse ante todo como aquello que expresa el "es" de la cópula: es el ser copulativo o lógico. En este sentido decimos que "es" todo aquello de que podemos formar una proposición. Su ser es concipi, un ser que en cuanto tal se da en y por el acto conceptivo de la intelección, un esse in anima. Este esse es de dos tipos. Hay un esse que además de ser in anima lo es también extra animam: es el ser que tiene algo independientemente de toda concepción, el ser real, el esse reale, el ser sustantivo. A él se opone aquello que

Por aquí viene el deslinde tanto de un realismo ingenuo achacado a la Escolástica como de un idealismo igualmente ingenuo que podríamos remontar al mismo Descartes, y desde luego a Kant. Cf. Xavier Zubiri, Inteligencia sentiente. "Inteligencia y realidad (Madrid: Alianza-FXZ, 1998), 177 178. El arte del oficio filosófico-fenomenológico consistirá en mantenerse sobre la afilada cima de la realidad del «de suyo» en tanto que alteridad radical, sin sucumbir a ninguno de los abismos. De ahí la necesidad de mantenerse en ese ámbito en el que la cosa se da; y sólo como la cosa se da, según las palabras de Husserl: «No hay teoría concebible capaz de hacernos errar en punto al principio de todos los principios: que toda intuición en que se da algo originariamente es un fundamento de derecho del conocimiento; que todo lo que se nos brinda originariamente (por decirlo así, en su realidad corpórea) en la "intuición", hay que tomarlo simplemente como se da, pero también sólo dentro de los límites en que se da». Edmund Husserl, Ideas relativas a una Fenomenología pura y una Filosofía fenomenológica (México: FCE, 1995), 58. 
sólo tiene un esse in anima, el ens rationis, pero que in re no tiene ni puede tener esse... En cambio, las cosas que tienen ser extra animam tienen existencia, son ens reale. Aquí, esse significa existir y, por tanto, actuar produciendo efectos, cosa que no se da en el ens rationis, en el ente irreal $»^{29}$.

Como se ve, partiendo del ens concipi la Escolástica llegó hasta el ens reale. El punto de partida parece ser el esse in anima; y si el esse in anima era además esse extra animam, entonces teníamos al esse reale ${ }^{30}$. Y este esse reale, por oposición al ens rationis ${ }^{31}$, fue conceptualizado como existencia: actuar produciendo efectos ${ }^{32}$. Por esta razón para la Escolástica el primer trascendental es precisamente el ens. Pero si sometemos a un análisis fenomenológico el ens reale de la Escolástica en tanto que existir, no topamos en primer lugar esa estructura analítica y genealógica que nos llevaría hasta el alma en tanto origen del ser. Si enfrentamos fenomenológicamente el ente

29 Xavier Zubiri, Sobre la Esencia, op. cit., 383-384.

30 Para la escolástica, dice Zubiri, esse reale es igual a existencia.

31 El ens rationis, a diferencia del esse reale, es una quimera, una ficción, un objeto fingido, algo, en definitiva, que no es real y que «no tiene más que un esse intentionale (...) un ser intencional». Xavier Zubiri, El hombre: lo real y lo irreal (Madrid: Alianza-FXZ, 2005), 16.

32 Las diversas corrientes escolásticas se distinguieron, entre otras cosas, por la explicación de la diferencia entre esencia y existencia. Étienne Gilson dice que la diferencia que se acusa entre Santo Tomás y Duns Scoto estriba en el Aristóteles que recibieron. Así, «verdad es que, técnicamente hablando, Santo Tomás debe más a Averroes y que Duns Escoto debe más a Avicena...» Étienne Gilson, op. cit., 591. Aunque ambos fueron muy creativos con la tradición aristotélica que recibieron, detrás tanto de Avicena como de Averroes se oculta «el necesitarismo griego del entendimiento, en una palabra, el Pensamiento Puro de Aristóteles; y este necesitarismo de lo inteligible es la sustancia misma de que será hecha siempre toda la filosofía, a no ser que se eleve, más allá del ser, hasta la existencia» Ibíd., 590. Mohamed Ábed Yabri dice que «en su demostración del primer principio (Dios), Avicena había seguido, por un lado, el camino inverso a los teólogos, que partían de la no-eternidad del mundo y su necesidad de un agente para demostrar la existencia del Creador; y por otro, el camino inverso a Aristóteles, que demuestra la existencia del Primer Motor desde la noción misma de movimiento. Avicena mantiene, como decíamos, que la reflexión en torno a la idea de existencia puede demostrar por sí misma la existencia necesaria per se, teniendo en cuenta que la división intelectual del ser implica que el existente debe ser necesario per se, posible per se, necesario por otro o simplemente contingente». Mohamed Ábed Yabri, El legado filosófico árabe (Madrid: Trotta, 2001), 152. Los filósofos y los teólogos cristianos harán por mostrar que Dios, el de la fe, está más allá que el ser de la metafísica. Así Duns Scoto: la metafísica deberá probar «que existe un primero en el orden del ser, y después, que ese primero es infinito [trascendental disyunto de las pasiones propias del ser]» Étienne Gilson, op. cit., 581. Éste es el límite de la metafísica. Ella no puede decir si ese primero infinito es Dios creador, amoroso, etc.: «a no ser que se eleve más allá del ser, hasta la existencia», dice Gilson. Y será la existencia de toda cosa, en cuanto actuación, la realidad «de suyo», de la que parte Zubiri. Se puede revisar, con gran provecho, lo que sobre el asunto de la esencia y la existencia dice Martin Heidegger en Los problemas fundamentales de la fenomenología (Madrid: Trotta, 2000), 111ss. 
real en tanto que existir, lo primero que nos es dado es su actuar en tanto que físico y no en tanto que ente. Lo único que me es dado es que esta cosa real actúa; o más bien, lo único dado es la actuación de esta cosa que existe, que es real, independientemente de si pertenece a esa estructura de ser que remonta al alma. Avanzando un poco más, y dislocando cualquier resabio de realismo ingenuo, fenomenológicamente la cosa es «de suyo», no extra animam, eso que la cosa realmente es. Por donde se ve que el primer trascendental es, pues, realidad, res. Constituye, junto con el unum, lo que «las cosas son "de suyo" en y por sí mismas» ${ }^{33}$.

\section{1. unum}

La realidad, siendo «de suyo» lo que es, res, es una. Es el otro trascendental por lo que ve a la cosa en y por sí misma, sin ninguna relación a nada más. Ya indicamos los atascos en los que la Escolástica se metió al conceptuar la unidad como indivisión del ente; indicamos también la propuesta de invertir los términos y de incluir el concepto de «función transcendental» para encontrar una mejor salida al problema. Con la diferencia de que aquí no se trata de indicar sobre la unidad del ente sino de describir fenomenológicamente la realidad en tanto una. Toda realidad es un sistema estructurado, es un constructo físico. Es una construcción física de notas; de unas notas físicas que forman un sistema. Aquí se ve, una vez más, que de lo que habría partir, si siguiéramos a la Escolástica, es del ens reale en tanto que reale. Porque es su actuar el que se nota; y este notarse del actuar remite a las notas que conforman "de suyo» la realidad en tanto actuante. Esas notas de la realidad «de suyo» en las que se nota dicha realidad tienen una estructura: unas son notas constitutivas o esenciales, otras son notas constitucionales y otras son notas adventicias. Todas estas notas conforman la realidad una. Un cambio mayor en una nota adventicia no altera la unidad de esta realidad. Si a un hombre le cortan un dedo o le hacen una transfusión 
de sangre no le tocan su unidad metafísica. Sin embargo, el cambio más pequeño en el subsistema de las notas constitutivas hará que la realidad en cuestión sea otra que la que era. Pero no se crea que las notas de la realidad fundan la unidad; es exactamente al revés: la unidad funda las notas. Así, el que quiere hacer, por ejemplo, un reloj o una silla no construye primero las piezas que conforman el reloj o la silla. No sucede así. Lo que hace es, simplemente, una silla o un reloj. La unidad de la cosa real «de suyo» es el supuesto primario en el orden ontológico o metafísico y en el orden epistemológico. «Desde el punto de vista de sus notas, la esencia constitutiva es el sistema de notas necesarias y suficientes para que la realidad sustantiva tenga todas sus demás notas. Desde el punto de vista de su unidad, la esencia constitutiva es unidad coherencial primaria ${ }^{34}$.

La unidad de la notas, sean estas las que talitativamente sean en cada cosa, constituye la realidad de la cosa misma. Por eso el unum es un trascendental: porque es anterior a las notas y es quien las ordena para constituir a esta realidad, para ser «de suyo» lo que es. Constitución y unum son exactamente lo mismo porque «constitución es el modo como toda realidad tiene de ser una en su multitud de notas, en su unidad esencial y sustantiva» ${ }^{35}$.

\section{c. Trascendentales complejos}

Res y unum son, pues, los dos trascendentales primeros de la cosa «de suyo». Todo aquello que sea «de suyo» será res y unum, una realidad. Ambos son trascendentales simples porque se refieren a la cosa «de suyo» en y por sí misma. Pero las cosas en y por sí mismas, «de suyo», «son también "de suyo" respectivas» ${ }^{36}$. Aquí aparecen otros trascendentales que ya no son simples sino complejos porque son propiedades de la cosa real «de suyo» en tanto respectiva también «de suyo». Estos trascendentales son mundo, aliquid, verum y bonum. Zubiri llama a estos cuatro trascendentales «complejos» porque

\footnotetext{
Ibíd., 342.

Xavier Zubiri, Sobre la realidad, op. cit., 117.

Xavier Zubiri, Sobre la Esencia, op. cit., 436.
} 
aunque «competen formalmente a cada cosa real por el mero hecho de ser real» ${ }^{37}$, sin embargo «expresan aquello que se sigue del puro carácter de realidad en orden a la multiplicidad de las cosas reales ${ }^{38}$. El primero formalmente de los cuatro, y hasta aquí no parece haber ninguna duda, es el mundo. Pero qué es el mundo, preguntamos por enésima ocasión; ¿̇por qué el mundo, que nunca figuró entre los trascendentales en la tradición, entra ahora en la estructura de la trascendentalidad? Es cierto que en la filosofía de Heidegger, aunque él no los llame nunca con ese calificativo, el ser del ente en tanto que sentido, el mundo y algunas otras cosas, por llamarlas de alguna manera, ocupan el puesto de una especie de estructura trascendental en el marco de una fenomenología hermenéutica que, por cierto, debe ser cuidadosamente deslindada, que no rechazada ni minimizada en tanto fenomenología, de una metafísica de génesis fenomenológico-husserliana como la de Zubiri que toma en serio el lema de ir a las cosas mismas, antes de ceder a la tentación heideggeriana que hermeneutiza todo lo que toca, dejando a las cosas en tanto cosas-sentido ${ }^{39}$. Al mundo como red de significaciones en tanto, según dice Heidegger, "“aquello en lo que" "vive" un Dasein fáctico en cuanto tal $»^{40}$, propio, reitero, de una fenomenología hermenéutica, Zubiri le opondrá como fundamento el mundo en tanto respectividad. «Las cosas, tales como son en realidad, son, ante todo,

Ibíd., 429 .

Ídem.

39 No está de más insistir en que la distinción entre cosa-real y cosa-sentido en Zubiri es fundamental, a más de ser su deslinde radical con Heidegger, según lo hemos comentado ya. El martillo funciona como martillo en el mundo respeccional en el que el martillo tiene el sentido de ser un martillo: una carpintería, clavos, madera, etc. Martin Heidegger, Ser y tiempo (Madrid: Trotta, 2003), 96-97. Hasta aquí Heidegger. Pero no se va a pretender, indica Zubiri, que la cosa-real martillo deje de ser tal cosa una vez que está fuera de ese mundo respeccional. Fuera de ese mundo respeccional el martillo aplaza las posibilidades de ser martillo y puede convertirse en un proyectil, en un adorno, en un pisa papeles, en basura, en un objeto para atrancar una puerta o una ventana, etc. Pero es que, según la tesis de Zubiri, el martillo no actúa sobre las demás cosas y sobre sí mismo en función de sus posibilidades de sentido. El martillo (caso de que fuera una cosa real), o cualquier otra cosa real, «actúa sobre las demás cosas y sobre sí mismo en virtud, formalmente, de las notas que posee». Xavier Zubiri, Sobre la Esencia, op. cit., 104. Tales como su peso, color, densidad, solidez, humedad, composición química, etc. Sobre esas notas, que son de la cosa-real «de suyo» están montadas todas las posibilidades de la cosa en tanto que cosa-sentido: martillo-proyectil-adorno, etc. Cf. también Xavier Zubiri, Inteligencia y razón (Madrid: Alianza-FXZ, 1983), 59-60.

Martin Heidegger, Ser y tiempo, op. cit., 93. 
cosas reales cada una en y por sí misma; pero además, estas cosas se hallan realmente vinculadas entre sí en una u otra forma» ${ }^{41}$.

La segunda parte de la oración es la que ahora nos interesa: las cosas están realmente vinculadas entre sí. El adverbio «realmente» no indica un mero modo de hablar. Lo que Zubiri está diciendo es que cada cosa real «de suyo» está realmente, físicamente, desde la propia estructura que la conforma, vinculada con las otras cosas reales. Una cosa real no es una mónada, o un objeto, o un ente ya constituido, que entonces sale y se relaciona con los demás. No se trata de esto. El vínculo físico y real que "de suyo» hay entre las cosas reales es anterior a toda relación extrínseca. Es más, todo tipo de relación, inclusive la más intrínseca e íntima entre las cosas reales, sólo es posible porque la cosa real «de suyo» está ya vinculada físicamente a todas las demás. Ese vínculo entre las cosas reales lo que indica es que las demás cosas son ya momentos físicos de la cosa real «de suyo», de uno o de otro modo. Cualquier otra conexión o relación está fundada ya siempre en esta vinculación física originaria. «Lo primario está en que esta conexión operativa se halla fundada en la constitución misma de las cosas, una constitución según la cual cada cosa es formalmente lo que es en realidad en función de la constitución de las demás cosas. No se trata, pues, de una conexión "operativa", sino de un carácter "Constitutivo" ... ${ }^{42}$. Ni siquiera se trata de una mera aperturidad física meramente potencial de una realidad sustantiva a otra por el carácter físico de sus notas, pero como sin tocar realmente a las otras realidades. Lo que la vinculación de las cosas realmente significa es la función (in actu exercitu) de la realidad de cada cosa en la constitución física de las demás. «Este carácter [constitutivo] no es consiguiente a cada cosa real, sino que pertenece intrínsecamente a su realidad formal, algo así como cada pieza de un reloj es por constitución algo cuya realidad es formalmente función de la constitución de las demás piezas» ${ }^{43}$. 
A esta vinculación intrínsecamente constitucional de las cosas reales «de suyo» Zubiri la llama con el nombre de respectividad: es el momento intrínseco y formal según el cual la constitución de una cosa real está en función de la demás cosas reales. Y aquí es donde está el mundo en tanto trascendental de la realidad en cuanto realidad. Mundo es «la totalidad de las cosas reales por razón de su carácter de realidad, esto es, en cuanto reales: la respectividad como modo o carácter de realidad» ${ }^{44}$.

Zubiri hace aquí esa distinción metafísica fundamental que necesitamos traer a cuenta a fin de aclararnos y precisarnos el mundo en tanto trascendental. Tal distinción es la que hay entre la cosa real en tanto realidad, por un lado, y la cosa real en tanto tal o cual cosa real. El ámbito de la realidad en tanto realidad es el ámbito trascendental, es el ámbito de la cosa real en tanto que siendo "de suyo» cosa real. En cambio, el ámbito de la cosa real en tanto que tal cosa es el ámbito de la talidad. El árbol y el libro, suponiendo que los dos fueran cosas reales, en tanto que cosas reales son mundanales; pero en tanto que cosas reales tales (árbol, libro) pertenecen a cosmos, a órdenes diferentes. La primera sería respectividad mundanal; la segunda respectividad talitativa. Y sólo la mundanal sería trascendental. De aquí lo que se sigue es que hay un solo mundo, el de la realidad en cuanto realidad, mientras que pueden existir infinidad de cosmos, de ordenaciones de las cosas talitativamente. «Este concepto de mundo es el primario y fundamental. Los demás conceptos de mundo presuponen éste. La filosofía actual (Heidegger) suele entender por mundo aquello en lo cual y desde lo cual el existir humano se entiende a sí mismo y se encuentra (entendiendo) con las demás cosas. Pero el mundo en este sentido se funda en el mundo como respectividad de lo real qua real $»^{45}$.

Una fenomenología hermenéutica se mueve, todo lo radicalmente que se quiera, en los cosmos de las talidades. Pero a la cosa en tanto

44 Ídem.

45 Ibíd., 428. 
que tal no le basta para ser tal que su sentido le venga abierto por la comprensión del Dasein. La cosa «de suyo» remite a una alteridad, que no puede sacar del hombre, sino simplemente actualizarse en él, dado el carácter talitativo de su estructura real. Es por eso que una metafísica de génesis fenomenológica puede remontar el ámbito del sentido de las talidades hasta el ámbito de la alteridad que es «de suyo» eso que realmente es.

Sólo porque el hombre es una realidad constituida qua realidad en respectividad a los demás, esto es, sólo porque el hombre es ya «mundanal» como realidad, puede hacer suyo el mundo, en el sentido existencial y vital, por «bosquejo». Mundanidad no es sino respectividad de lo real en tanto realidad ${ }^{46}$.

En definitiva, res, unum y mundo son los primeros tres trascendentales que estructuran el orden trascendental de modo riguroso: el mundo sigue al unum y éste a la res. El primero es un trascendental complejo porque se refiere al vínculo físico entre las cosas reales, y los dos primeros son trascendentales simples porque se refieren a la realidad en y por ella misma. Hasta aquí, por lo menos dentro del sistema mismo del orden trascendental propuesto, no hay mayor problema. Amén del escozor que a un escolástico, a un kantiano y aún a un husserliano y, desde luego, a un heideggeriano, podría provocarle la filosofía primera de Zubiri. Hasta aquí, digo, no hay mayor problema. Pero las incongruencias metodológicas, por un lado, y los nudos ${ }^{47}$, por otro, aparecen ahora ya. Y recuérdese que nos falta pasar por el aliquid, y sobre todo por el verum y el bonum.

Detengámonos brevemente en lo que considero una incongruencia metodológica. Zubiri no se cansa de repetir a lo largo y ancho de su obra que no pretende crear ni construir meras teorías; que el imperativo metodológico que le anima es la descripción de lo meramente dado, la simple descripción de los hechos. Sin embargo, todo el que haya hecho el ejercicio más elemental para describir lo

46 Ídem

47 Cf. Antonio Pintor-Ramos, Nudos en la filosofía de Zubiri (Salamanca: Publicaciones Universidad Pontificia, 2006), 7. 
meramente dado, sabe que su descripción lleva ya envuelta una teoría (y unos prejuicios) respecto de la cual debe mantener siempre el ojo avizor. Zubiri hace las tres cosas: describe lo dado, propone teorías y se mantiene ojo avizor para volver a la descripción de lo dado; hace descripciones fenomenológicas, se adentra en teorizaciones metafísicas (a veces queriéndonos convencer de que son meras descripciones) y vuelve, ojo avizor, a la descripción de lo dado. La incongruencia metodológica a la que ahora me refiero es grave por las facturas fenomenológicas que luego se pretenden cobrar desde la metafísica. Voy a explicarme. Nos ha dicho Zubiri que mundo es un trascendental complejo porque, a diferencia de los simples (res, unum) que se refieren a la cosa en y por sí misma, este se refiere a la cosa real en y por sí misma en tanto vinculada con las demás cosas reales. Mundo es, pues, según dijimos ya, la totalidad de las cosas reales en tanto que reales, no en tanto que totalidad. Por esto, y sólo por esto, no se puede hablar más que de un solo mundo, el mundo de la realidad. Mientras que, talitativamente, las cosas pueden vincularse y desvincularse de maneras infinitas, formando así infinidad de cosmos posibles. Puede haber cosas que no tengan nada que ver entre sí cósmicamente; pero pertenecerán al único mundo de la realidad en tanto realidad. ¿Pero qué pasa con Dios? Entonces le oímos decir al Zubiri metafísico que «hay una realidad, Dios, que es formalmente extramundanal $»^{48}$. Y justifica este salto metodológico que iría de la fenomenología a la metafísica del siguiente modo:

Es verdad que mientras no se haya probado su existencia [la de Dios] no puede uno apoyarse en ella, y en el exordio de la metafísica no está aún probada la existencia de la realidad divina. Mas aunque esta realidad no esté probada al comienzo de la metafísica, tampoco está excluida, y, por tanto, es lícito contar presumiblemente con ella en la teoría de los trascendentales ${ }^{49}$.

Ya se ve que Zubiri ha decidido que es lícito contar, en una teoría de los trascendentales, con la existencia de la realidad divina. 
Ya advertido, uno puede continuar sin problema si así lo decide. Dios, que es una realidad absolutamente absoluta, es formalmente «irrespectivo, extramundano, porque es realidad esencialmente existente $»^{50}$. Mientras que el mundo es respectivo a Dios porque las cosas son realidades relativas, Dios no es respectivo al mundo porque él es una realidad absolutamente absoluta. Sí; pero entonces mundo no puede ser un trascendental si hay una realidad, la divina, a la cual no conviene esa propiedad. Sin embargo, dice Zubiri que si mundo designa «aquel carácter según el cual la realidad en cuanto tal es forzosamente y por razón de la realidad, o bien respectiva (mundanal), o bien irrespectiva (extramundanal)» ${ }^{51}$, mundo designa entonces un carácter «disyunto» ${ }^{52}$ según el cual la realidad absolutamente relativa es respectiva $\mathrm{y}$, por tanto, mundanal, mientras que la realidad absolutamente absoluta es irrespectiva y por tanto extramundanal. Es por esto por lo que mundo es un trascendental complejo y disyunto. Sin embargo, y concediendo un poco, este desliz de metafísica extramundana en un tratado de metafísica mundana a secas, que pretende volver cada vez a la descripción de lo dado, podría dejar al mundo en tanto que trascendental sin otro calificativo que el de complejo, porque también es lícito no contar con la existencia de la realidad divina en una teoría de los trascendentales. El problema de haber contado con ella es que el mundo, además de complejo deberá ser calificado también de disyunto, restándole «extensión»a su trascendentalidad, con la agravante de continuar la descripción del orden trascendental sobre un calificativo del mundo, como es el caso de «disyunto», que no pertenece en modo alguno a lo dado. Hasta aquí el reparo al salto metodológico. Me referiré ahora al nudo indicado antes.

$50 \quad$ Ibíd., 431.

51 Ídem.

52 El concepto está tomado de Duns Escoto, como Zubiri mismo lo reconoce (Sobre la Esencia, 431). Aunque dice que Escoto lo forjó para otras propiedades, pues él nunca pensó que mundo fuera un trascendental. Jean-Francois Courtine, op. cit., 375. 


\section{Un nudo en el orden trascendental de la realidad}

Después de mundo vienen los otros tres trascendentales: aliquid, verum y bonum. También son complejos, como mundo: se refieren a las cosas en tanto vinculadas a las otras cosas reales. Pero a diferencia de aquel que es complejo-disyunto, estos tres son complejosconjuntos porque se pueden decir sólo de las realidades respectivas: los tres «expresan, en efecto, lo que es intrínsecamente el carácter de realidad de cada cosa como referibilidad a las demás. Y esta referencia no es sino la respectividad de lo real qua real, esto es, el mundo» ${ }^{53}$.

Se puede o no estar de acuerdo con Zubiri respecto a que las cosas sean así. Lo que es verdad es que a él, hasta el momento, no le cabe la menor duda de que realmente las cosas son así. Sin embargo, sí le cabe la duda, como ya lo apuntamos, cuando se trata de ponerle fundamento al aliquid, al verum y al bonum. Obviamente, el fundamento de todos los trascendentales es la realidad; pero el orden trascendental tiene una estructura según la cual unos trascendentales son formalmente primero que otros. Así, dice Zubiri en Sobre la Esencia que «mundo es el primer trascendental complejo, el trascendental fundante de todos los demás trascendentales complejos: aliquid, verum, bonum» ${ }^{54}$. No hay la menor duda de que el aliquid tiene por fundamento al mundo: «Sólo porque una res en cuanto res es respectiva a las demás, puede ser y es un aliud respecto de ellas» ${ }^{55}$. No hay ninguna duda tampoco en Sobre la Esencia de que el verum y el bonum encuentran su fundamento en la respectividad misma de la realidad que es el mundo: el verum y el bonum «envuelven una respectividad de la realidad inteligente y volente a la realidad inteligida y querida $»^{56}$. Hay que recordar que no pertenece al orden trascendental de la realidad humana el ser inteligente y volente; que la inteligencia y la voluntad pertenecen al modo propio, especial,

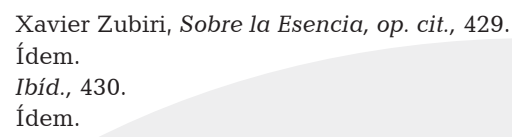


de la realidad humana, a su talidad. Pero que estas dos propiedades de la talidad humana tienen una función trascendental en orden a la verdad y a la bondad de la realidad en cuanto tal. Podría ser de otro modo, es verdad. Pero el hecho inconcuso es que es así: «Sólo porque la cosa real inteligente y volente está en el mundo de las demás cosas reales, sólo por esto es posible que haya intelección y volición y, por tanto, verum y bonum trascendentales» ${ }^{57}$. Como se ve, hay aliquid, verum y bonum, formalmente, sobre el mundo. Podríamos ensayar el siguiente esquema sobre la estructura trascendental de la realidad según Zubiri:

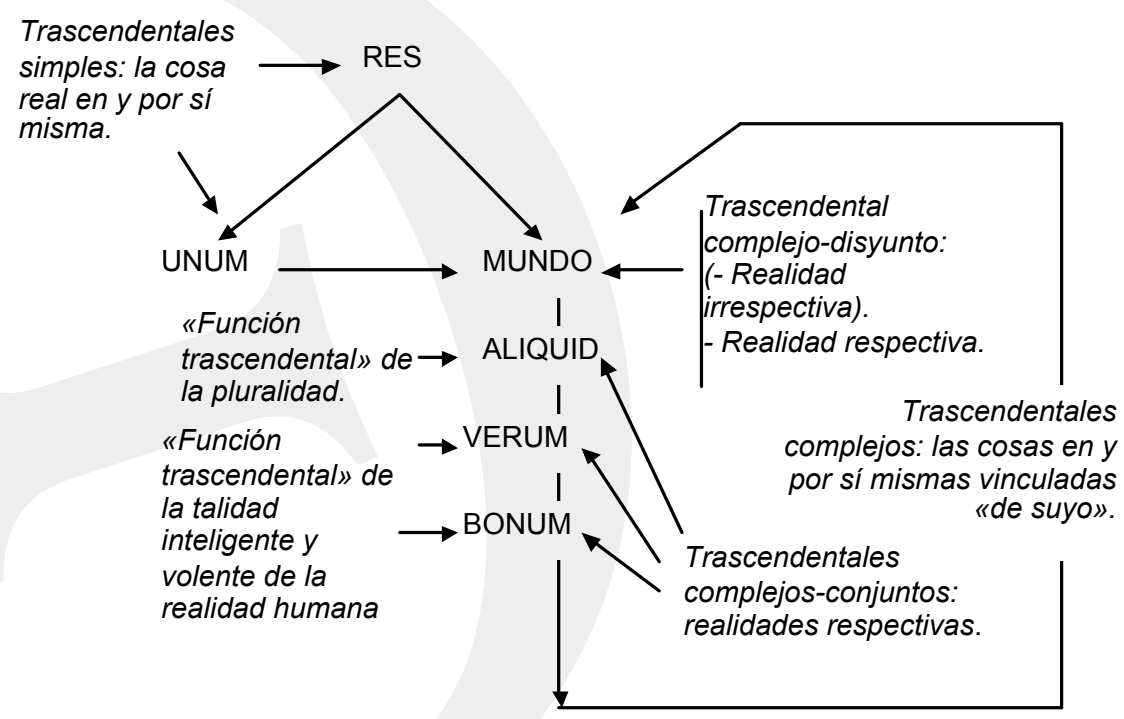

¿Y el ser dónde quedó? Porque ya se ha dado cuenta de toda la estructura trascendental de la realidad y, como pudimos constatar, el ser no asomó. Zubiri parece tener con el ser y la estructura trascendental de la realidad un mar de problemas. Mientras que en Sobre la Esencia dice que mundo es el trascendental que funda a los tres trascendentales conjuntos, en Sobre la realidad dice que es el ser, actualización de la cosa real en el mundo, la que los fundamenta. 
Mientras que en Sobre la Esencia afirma que los trascendentales complejos son de la cosa-real-una en tanto mundanal, en Sobre la Realidad lo que dice es que el consabido aliquid, verum y bonum deben decirse de la cosa real-una-mundanal en tanto siendo, en tanto actualizada mundanalmente: «La actualidad de la res, de la nuda realidad en ese mundo es lo que llamamos ser $y$, precisamente porque el ser es una actualidad en una respectividad, cada realidad es como ser, constitutivamente, un aliquid, un verum, y un bonum $»^{58}$. Del modo que sean las cosas, hay que advertir que está operando, en una pretendida descripción de lo dado, aquella distinción metafísica entre realidades respectivas y realidades irrespectivas que hizo del mundo un trascendental disyunto, al que «si llamamos "mundo" es porque en este caso calificamos a la disyunción por su término más claro, y quoad nos el único inmediatamente innegable» ${ }^{59}$. Si la actualidad de la realidad respectiva en el mundo es el ser, y Dios es una realidad irrespectiva, no sólo extramundanal sino, y sobre todo, extramundanal, entonces, como no tiene mundo, tampoco tiene ser. Por tanto, ¿̇tampoco el aliquid, el verum y el bonum pueden ser trascendentales de Dios? iAh, pero es que «el mundo es respectivo a Dios, pero Dios no lo es al mundo»! ${ }^{60}$ Entonces: «Sólo porque la cosa real inteligente y volente está en el mundo de las demás cosas reales, sólo por esto es posible que haya intelección y volición y, por tanto, verum y bonum trascendentales» ${ }^{61}$.

Como se ve, la intromisión de esa idea metafísica sobre Dios nos ha metido en un callejón sin salida que, por ahora, no vamos a seguir. De lo que queremos hacernos cuestión es de la estructura de las realidades mundanas sin más que son las únicas que nos son dadas. ¿De dónde están cogidos el aliquid, el verum y el bonum? ¿del mundo o del ser? Este es realmente el problema. ¿̇ué es, en definitiva, el ser?, ¿̇tiene pertinencia el ser en una estructura tras-

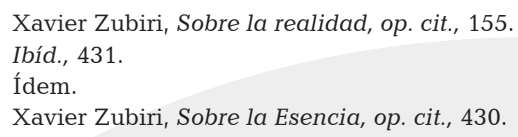


cendental de la realidad como la que Zubiri propone?, żo será acaso que a la hora de querer introducirlo en dicha estructura por razones político-filosóficas, que atañen tanto a la estructura trascendental como al ser, parece no tener cabida?

\section{El ser en el orden trascendental de lo real}

Parece, de cualquier modo, que para salvar al ser en tanto que actualidad habrá que recurrir a una distinción metafísica, no fenomenológica, entre la nuda-realidad-una, por un lado, y la nuda-realidad-una en tanto siendo en la actualidad respeccional que es el mundo. Sólo tenemos experiencia de realidades-unas-mundanales-siendo-aliquidverum-bonum. Si por un imposible fenomenológico y metafísico nos fueran dadas sólo realidades-unas(-mundanales), entonces no tendríamos ni ser, ni aliquid ni verum ni bonum. Si hay distinción física entre mundo y ser, como creo que la hay, entonces pienso que el ser en tanto que actualización debe formar parte de la estructura trascendental de la realidad propuesta por Zubiri. Efectivamente, la mundanidad es el carácter respectivo que tiene lo real por ser real. Lo real tiene un momento formalmente mundanal, según el cual la totalidad de los actos reales están vinculados, no por ser totalidad sino por ser reales. Pero no sería suficiente que la cosa real «de suyo» sea ya de por sí mundanal; es necesario que la cosa se actualice en el mundo en tanto tal cosa real o tal otra cosa real. Es necesario que la cosa real-una-mundanal sea, esté presente desde ella misma siendo «de suyo» lo que es. Entonces, y sólo entonces, la cosa real-una-mundanal-siendo podría ser otra-verdadera-buena. Lo que le da, por decirlo así, a la cosa-real-unamundanal su carácter cursivo entre las cosas reales es precisamente el ser. «El verum, el bonum y el aliquid no son sino modos de ser $y$, por consiguiente, modos en respectividad, modos de las realidades sustantivas en respectividad $»^{62}$. Así nos quedaría el esquema de la estructura trascendental de la realidad, ya con el ser incluido: 


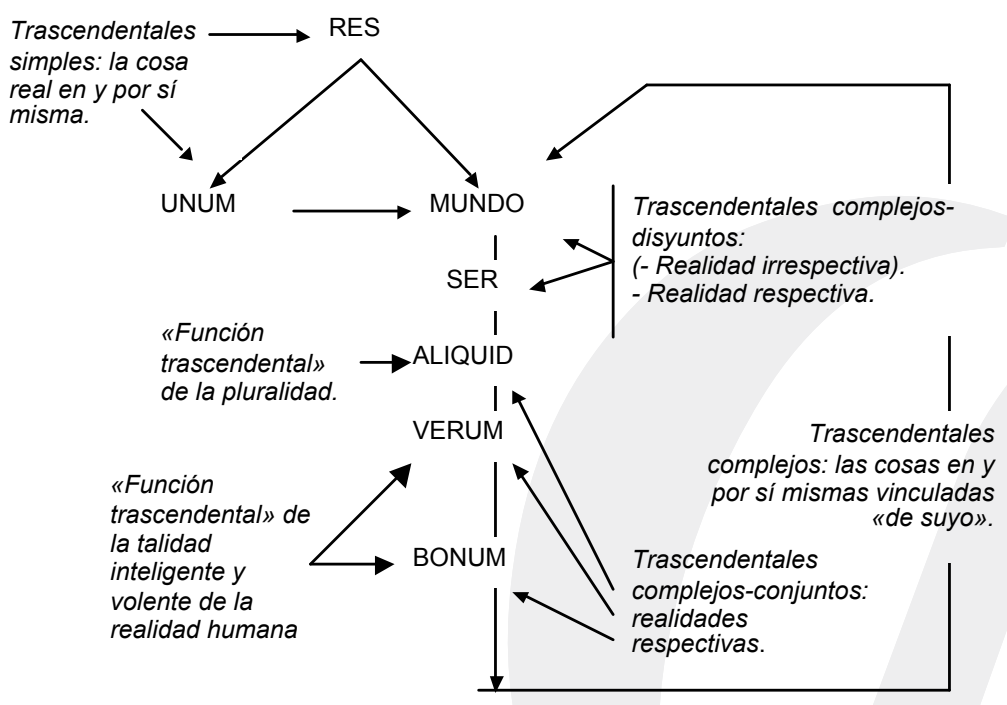

El ser sería también un trascendental complejo-disyunto. Complejo porque el ser es de la cosa-real-una, no en y por sí misma, sino en tanto que está vinculada a las demás: la cosa-real-una-mundanal se actualiza, es, con/junto/frente a otras cosas reales. Materialmente, la cosa-real-una no necesita ser, actualizarse en el mundo, para ser cosa-real-una. La cosa real constituida factualmente está así constituida y ya. No necesita el ser para completar, por decirlo así, su constitución real. Sin embargo, formalmente no hay cosa-realmundanal que no sea, que no se actualice en el mundo. Es más, lo primero empíricamente para nosotros, recordando aquella vieja expresión de Aristóteles, es el ser, la actualización de la cosa real en el mundo. Hay que hacer un ejercicio fenomenológico que haga, sólo metodológicamente, epojé del ser para dar con la realidad así actualizada en el mundo, con aquello que es primero «de suyo». Y todavía más: hay que ensayar una teoría metafísica para ver el modo de explicar la estructura trascendental de esa realidad, a partir de lo dado en tanto que siendo, es decir, en tanto que actuando.

Con ser un trascendental complejo, el ser es sin embargo un trascendental disyunto. Porque si hacemos caso a Zubiri y las realidades, efectivamente, son o bien respectivas o bien irrespectiva, bajo la hipótesis 
de la existencia de la realidad divina en tanto irrespectiva y por tanto extramundana, nos queda entonces que toda realidad intramundana es respectiva y mundanal $\mathrm{y}$, por tanto, actual en ese mundo, siendo en el mundo. Digamos aquí también que si omitiéramos el carácter disyunto del ser, como en su momento el del mundo, por imperativos estrictamente fenomenológicos, tanto mundo como ser conservarían su carácter trascendental sin ningún menoscabo. Pero Zubiri, como Duns Escoto, quiere abonar el camino para hacer teología y por eso deben incluir y conservar la disyunción de algunas propiedades de la realidad.

Por otro lado, también la distinción entre ser y mundo puede parecer una sutileza. Creo, sin embargo, que también aquí la realidad humana, en sentido estricto lo único fenomenológicamente dado, puede arrojar luz. En efecto, la realidad-humana-una está vinculada desde su propia constitución con las otras realidades humanas de modo físico, biológico, psicológico y filético ${ }^{63}$. Es esta vinculación constitucional, llamada respectividad, la que constituye el mundo, en este caso de la realidad humana por ser realidad; respectividad que alcanza a todas las realidades sólo por ser realidades. Que las realidades humanas están constitucionalmente vinculadas es un hecho anterior a todo acto volitivo e intelectivo de querer pertenecer a éste o a aquel otro grupo social ${ }^{64}$. Es el ámbito de la realidad mundanal. Ahora bien, pertenecer a este grupo social o a aquel por determinadas razones, no es algo que competa a la nuda realidad

Dice Zubiri que «el phylum es una realidad física, mucho más real aún que lo que pueda serlo el "campo" electromagnético, gravitatorio, etc. Y aquellos caracteres constitutivos por lo que cada individuo pertenece real y físicamente a un phylum determinado, son justo los que constituyen la especie: la esencia individual ha quedado especificada. En este sentido, preguntarnos qué es algo, es preguntarnos no por la clase de realidades a que pertenece, sino por el phylum del que y en que emerge físicamente a la realidad y al que pertenece por su esencia constitutiva». Xavier Zubiri, Sobre la Esencia, op. cit., 235; Cf. Ibíd., 236, 240, 312, 315-320.

64 Zubiri dice que la expresión «los otros» es «la forma primaria como las demás personas existen en la hominidad del niño; es una forma según la cual precisamente no son "otros", esto es, ajenos a mí, sino que por el contrario son "míos" son mi madre, mi padre, mi hermano, etc. Son algo que es "mío". El niño y sus progenitores, por ejemplo, repiten gestos a los que se siguen respuestas. Así es como se van formando unidades humanas dentro del mundo y sobre todo gracias a este mundo. Sin él no se podrían formar esas unidades. Pero esas unidades no son los "otros", sino algo que humanamente pertenece al niño, son algo "mío" diríamos hablando en su lugar. Ciertamente son algo distinto de mí, si no, no serían míos; pero su manera de ser distintos es tal que los descubro como míos». Xavier Zubiri, Tres dimensiones del ser humano: individual, social, histórica (Madrid: Alianza-FXZ, 2006), 46. 
en tanto mundanal. Eso lo tiene que hacer la realidad humana en tanto actualizada, en tanto siendo, en el mundo; es decir, en tanto yo.

Mundo y ser se distinguen: aquel es mera respectividad de realidad; este tiene que ir haciéndose, su carácter es cursivo, debe forjar, en el caso del hombre, la figura del propio yo. Ahora bien, la cursividad del ser, que reobra sobre el mundo de la realidad-una, funda, es posibilidad de, el aliquid, el verum y el bonum. Si no hubiera más que res-unum-mundo quedaríamos sumidos en la indiferencia de la totalidad vacía. Pero res-unum-mundo tiene el carácter de un «in essendo», de estar siendo. Y este estar siendo del ser, del «in essendo», es precisamente el tiempo. El modo de ser del esse es el tiempo, que reobra en tanto esse tempóreo sobre la realidad-una-mundanal, fundando, por enésima vez, el aliquid, el verum y el bonum.

Ahora bien, no debe olvidarse que este es un análisis filosófico de los momentos de la cosa real; y que lo que está allende la puerta de mi estudio es un árbol que crece, un pájaro que canta, unas ardillas que comen. Realmente nada más; pero realmente nada menos.

\section{Conclusión}

La filosofía de Zubiri es una filosofía de la realidad, no del ser. Y aunque no se trata de una mera inversión de términos, como el propio Zubiri demuestra contundentemente, sí se heredan, sin embargo, un abanico de problemas que en la tradición estuvieron adscritos a la ontología, como es el caso precisamente del orden trascendental. Hemos tratado de dar cuenta tanto de la crítica del filósofo español a ese orden trascendental como de su misma propuesta.

Termino subrayando dos ideas que siguen haciendo problema en la misma propuesta de Zubiri. La primera es la que atañe al lugar del ser en ese orden trascendental; porque parece que él mismo no está tan seguro cuál es el lugar que le corresponde. Pero esta inseguridad sólo muestra desde otra óptica que el ser como actualidad de lo real en el mundo es siempre un momento 
derivado de la realidad, al grado que su lugar en el orden trascendental no está tan claro, al menos para el propio Zubiri. Leyendo cuidadosamente los textos y atendiendo a las cosas mismas es que propongo un esquema del orden trascendental en el que el ser encuentra plena cabida.

La otra idea a subrayar es la del mundo como trascendental disyunto. En una metafísica intramundana no habría necesidad de calificar y acotar la trascendentalidad del mundo por el lado de la disyunción. Pero en Zubiri está operando el teólogo que lleva dentro y sobre todo el creyente, el filósofo que tiene fe. Y esto es precisamente lo que hace que mundo tenga que ser acotado por la disyunción para que la metafísica intramundana conecte con la teología casi "naturalmente". Los filósofos no creyentes, o demasiado exigentes con el método, encontrarán esta disyunción como inaceptable; los filósofos que también son teólogos, sin embargo, encontrarán el camino para dar cuenta de esa realidad absolutamente absoluta que es Dios.

\section{Bibliografía}

Alluntis Learreta, Félix. «Meditaciones zubirianas. Talidad y transcendentalidad». Letras de Deusto 20 (1990): 109-131.

Aísa, Isabel. «De la posibilidad de perspectivas o niveles de la transcendentalidad. A propósito del orden transcendental de X. Zubiri». Thémata 4 (1987): 7-13.

Arellano, Jesús. «La idea del orden transcendental». Analecta Husserliana 29 (1990): 275-284.

Castilla y Cortázar, Blanca. «El orden transcendental en Xavier Zubiri». Anales de la Real Academia de Doctores (Madrid) 6 (2002): 19-46.

Courtine, Jean-Francoise. Suarez et le système de la métaphysique. París: Presses Universitaires de France, 1990. 
De Boni, Luis Alberto. «La metafísica escotista de Dios en el De Primo Principio. Duns Escoto y el argumento anselmiano del Proslogion». En Francisco Bertelloni, Francisco y Giannina Burlando, eds. La Filosofía Medieval. Madrid: Trotta-CSIC, 2002.

Ferrater Mora, José. Diccionario de Filosofía. Barcelona: Ariel, 2001. Gilson, Etienne. La Filosofía en la Edad Media. Desde los orígenes patrísticos hasta el fin del siglo XIV. Madrid: Gredos, 1999.

El ser y los filósofos. Pamplona: EUNSA, 2005.

Heidegger, Martin. Ser y tiempo. Madrid: Trotta, 2003.

. Los problemas fundamentales de la fenomenología. Madrid: Trotta, 2000.

Husserl, Edmund. Ideas relativas a una Fenomenología Pura y una Filosofía Fenomenológica. México: FCE, 1995.

Kant, Emmanuel. Crítica de la razón pura. Madrid: Alfaguara, 2002.

Oñate y Zubía, Teresa. Para leer la Metafísica de Aristóteles en el siglo XXI. Análisis crítico hermenéutico de los 14 lógoi de Filosofía Primera. Madrid: Dykinson, 2001.

Pintor-Ramos, Antonio. Nudos en la filosofía de Zubiri. Salamanca: Publicaciones Universidad Pontificia, 2006.

. «La transcendentalidad y los transcendentales en Zubiri». En Vázquez, M. J. et Alter, eds. Experientia et sapientia. Estudios dedicados a la memoria de Ángel Álvarez Gómez. Compostela: Universidad de Santiago de Compostela, 2007.

Yabri, Mohamed Ábed. El legado filosófico árabe. Madrid: Trotta, 2001. Zubiri, Xavier. Sobre la Esencia. Madrid: Alianza-FXZ, 1998. . Inteligencia sentiente. ${ }^{*}$ Inteligencia y realidad. Madrid: Alianza-FXZ, 1998. . Inteligencia y razón. Madrid: Alianza-FXZ, 1983. 
. Los Problemas fundamentales de la metafísica occidental. Madrid: Alianza-FXZ, 1995.

. Sobre la realidad. Madrid: Alianza-FXZ, 2001.

. El hombre: lo real y lo irreal. Madrid: Alianza-FXZ, 2005. . Escritos menores (1953-1983). Madrid: Alianza-FXZ, 2007.

. Tres dimensiones del ser humano: Individual, social, histórica. Madrid: Alianza-FXZ, 2006.

Recibido: septiembre de 2011 Aceptado: enero de 2012 